\title{
Learning Simple Perfect Tenses Using Implicit and Explicit Recasts
}

\author{
Sepehr Enjili ${ }^{1}$, Asgar Mahmoudi ${ }^{2,}$ * \\ ${ }^{1}$ Department of English, Ardabil Science and Research Branch, Islamic Azad University, Ardabil, Iran \\ ${ }^{2}$ Department of English Language, Ardabil Branch, Islamic Azad University, Ardabil, Iran \\ Email address: \\ S.Enjili92@gmail.com (S. Enjili), Mahmoudi301@gmail.com (A. Mahmoudi) (Corresponding Author)
}

\section{To cite this article:}

Sepehr Enjili, Asgar Mahmoudi. Learning Simple Perfect Tenses Using Implicit and Explicit Recasts. International Journal of Language and Linguistics. Vol. 3, No. 4, 2015, pp. 258-265. doi: 10.11648/j.ij11.20150304.20

\begin{abstract}
Numerous studies have been focused on corrective feedback (CF), specifically recasts. These studies have identified, classified, and explained their acquisitional effects. In terms of acquisitional effects, however, it seems that the studies have not yet covered all areas of grammar which constitutes a very broad range of issues. This study was an attempt to address this problem to some extent by investigating the effects of implicit and explicit recasts on the acquisition of simple perfect tenses (simple present, past, and future perfect tenses). In a within-between pretest-posttest group design, 45 Iranian students of English as a foreign language were assigned to two experimental and one control groups and underwent a treatment which lasted for 15 sessions. The students then were tested on their ability in correct application of simple perfect tenses. Following that, the collected data were subjected to different statistical tests, including MANOVA. The final results affirmed the effectiveness of recasts in improving the acquisition of simple perfect tenses. Of the two types of recasts-explicit vs. implicit — used in the study, explicit recasts proved to be more effective. Among the three tenses studied simple present perfect and simple future perfect tenses seemed to be more significantly affected.
\end{abstract}

Keywords: Implicit, Explicit, Recast

\section{Introduction}

Training for all students to be fluent and accurate has been a long-standing desire of all teachers. To find out what might fulfill this desire, researchers have tried many situations and many different ways. Correcting students according to their mood and morale and by not interrupting the natural flow of communication has appeared to be of especial interest.

Corrective feedback (CF) has been at the core of discussions and the subject of much debate exactly for these reasons. The last 10 years have witnessed an increase in the number of studies that have examined the effects of corrective feedback on second language learning. This includes both descriptive and experimental research examining a wide range of variables (e.g., type and amount of feedback, mode of feedback, learners' proficiency levels, and attitudes toward feedback). One of the reasons for this increased interest in $\mathrm{CF}$ appears to be related to the observation that despite the fact that L2 learners in communicative classrooms attain relatively high levels of comprehension ability and, to some extent, fluency in oral production, they continue to experience difficulties with accuracy (Harley \& Swain, 1984; Lightbown, Halter, White \& Horst, 2002; Lightbown \& Spada, 1990, 1994; Schmidt, 1983, 1990, 2001).Low levels of grammatical accuracy have been interpreted as evidence against the sufficiency of comprehensible input and exclusively meaning based instruction (Doughty \& Williams, 1998; Long, 1991; Long \& Robinson, 1998; Rutherford \& Sharwood Smith, 1985; Spada, 1997; White, 1987).

Corrective feedback takes the form of responses to learners" utterances containing an error. The responses can consist of (1) an indication that an error has been committed, (2) provision of the correct target language form, (3) metalinguistic information about the nature of the error, or any combination of these. Lyster and Ranta (1997) distinguish the following corrective feedback types:

* Explicit correction- this refers to the explicit provision of the correct form together with an explicit indication that 
what the learner said was incorrect (e.g., asking students directly to use or avoid a structure.)

* Recasts- a reformulation of all or part of a learner's utterance, (full recast vs. partial recast), minus the error.

* Clarification request-an indication that the learner's utterance has been misunderstood (e.g., 'pardon?').

* Elicitation- an attempt to directly elicit the correct form from the learner (e.g., prompts involving partial repetition of the learner's utterance with a blank for the learner to complete).

* Metalinguistic feedback- comments, information or questions related to the well-formedness of the learner's utterance without explicitly providing the correct form.

One of the moot points in this categorization is related to Recasts. Long (1996) considers recasts very effective and useful in promoting second language development. In other studies recasts are estimated to account for about 60 percent of all feedback moves in classroom atmospheres. Taking these claims into account, one still cannot be confident that justice is done to recasts in exploring their effects on language learning. This triggered the implementation of this study with the hope that it might bridge the gap. However, for the feasibility considerations, among all skills and subskills, it was grammar and among all grammatical elements, it was simple perfect tenses that were chosen due to their frequent use. Moreover, these three tenses were given priority because intuitively their correct application presents a big challenge to students.

Moinzadeh, Rassaei, and Youhannaee (2012) investigated recasts, modified output and L2 development in a case of Persian EFL learners. The study was designed to compare the effectiveness of recasts which triggered learners' modification to their incorrect forms with recasts which triggered no modified output. To meet this end, 60 Iranian EFL learners randomly selected from two EFL classes received recasts for their errors during task-based interactions with their interlocutors. Using a tailor-made design, the efficacy of recasts which were followed by learners' modified output was compared with the efficacy of recasts which triggered no modified output. The final results of the study showed that recasts which were followed by learners' modified output were more effective than recasts which prompted no modified output on promoting L2 development.

Pazoki and Rezaei (2013) conducted a research to investigate the role of recast on left hemisphere dominant vs. right hemisphere dominant Iranian EFL learners. Ninety eight adolescent EFL learners who were studying English in language centers in Iran were used to collect data. Of the two left brained groups, one group was assigned as the experimental and the other as the control group and the same procedure was followed for the two right brained learners. While the two experimental groups were provided with recast, the two control groups received no recast during the study. The analysis of the participants' performance on the posttest demonstrated that the experimental groups outperformed the control groups, and left brained learners more than right brained learners benefited from recast. As a result, the efficacy of recast in establishing new grammatical knowledge was proved. Further, the brain dominancy of the learners did affect the degree of the utility of recasts in developing grammar knowledge. The present study has pedagogical implications for both English language learning and teaching.

\section{Research Hypotheses}

The research hypotheses of this research were:

$\mathrm{H}_{0}$ 1: Implicit and explicit recasts do not affect learners' acquisition of simple perfect tenses differently.

$\mathrm{H}_{0} 2$ : Explicit and implicit groups are not separated by a combination of scores on all dependent variables.

\section{Participants}

The participants were 56 students enrolled in the English Language Center in Ardebil, Iran. Before starting the research, all of them were informed about the study, its purposes and aims. They all were assured that the results of their performance will be kept anonymous. After being informed, all of them expressed their willingness to participate in the study. All participants were native Iranian students and their ages ranged from 15 to 32 with a language learning experience of 3 to 5 years. None of the participants reported having been to any English speaking country. Prior to the beginning of the study, in order to ensure that the participants represented the same population, a proficiency test, was given to the available population from which the sample was derived. Only students who were at the intermediate level were allowed to participate in the study. Learners who missed the treatments or tests were also excluded from the analysis $(n=11)$. These measures dwindled the overall pool of students to 45 who were then randomly assigned to two experimental and one control groups. The groups were called ERG, standing for Explicit Recast Group, IRG, standing for Implicit Recast Group, and NRG, standing for No-Recast Group. The courses were offered for seven weeks and three sessions each week amounting to 4.5 hours a week and 31.5 hours for each group totally. During these courses, the students were provided with some communicative tasks and activities including information gap, storytelling, and discussions. Of the twenty one sessions, six sessions were spent on piloting of the study and giving pretests and posttests to the participants. The genuine treatments lasted for only 15 sessions.

\section{Research Design}

A within-between pretest-posttest group design was used to identify the effects of implicit and explicit recasts on different types of simple perfect tenses. As another objective, it was investigated if the final outcomes could separate participants in terms of the kind of treatment they received 
and if there was any interactions between the outcome variables.

\section{Procedure}

The study itself included proficiency test administration, pretest, treatment sessions, and posttest. The first session was allotted to the proficiency test which consisted of three main parts, listening, reading and grammar. Participants were asked to complete 24 items in 30 minutes. The answer sheets were scored and sorted out. After that, 45 intermediate students, those scoring above 20, were selected based on the criterion introduced at the back of Interchange 2 textbook of which the proficiency test was derived. The students were then randomly assigned to three groups of 15, two experimental and one control. Then the pretest was administered to determine the linguistic knowledge of the participants before receiving any instruction, and check for the homogeneity of the groups and normal distribution of the scores. The 15 treatment sessions were divided into 3 five-session phases each covering one of the targeted tenses with relevant activities. Tenses were taught inductively and any difficulty in students' application of perfect tenses was addressed using the recast type decided for that phase.

A description of the groups in the study is given below.

* Explicit Recast Group (ERG). When the teacher encountered an error related to the target grammatical structure, the segmented explicit recast was used. The teacher started rephrasing the erroneous utterance that had been made by the student. The rephrased utterance was error free and the ill-formed part was either removed or repaired. Segmented (explicit) recast is different from implicit recast in that the replaced element is stressed. The following example illustrates how explicit (segmented) recast was used:

T: Talk about the place that you stayed on your vacation.

$\mathrm{S}$ : Teacher..... we stayed in a tent because we did not book a hotel in advance.

T: Oh.... You had not booked a hotel in advance.

S: we had not booked. (Uptake)

It is worth mentioning that the teacher reformulated utterance was noticeable by emphasizing the replaced segment. The uptake following the teacher's reformulation shows that the student understood the corrective nature of the teacher's utterance.

* Implicit Recast Group (IRG). After facing errors, the teacher identified those related to the target structure and provided students with the implicit recast. The implicit recast, used in this study, was defined as error free students' rephrased utterances. The reformulated utterance did not impair the flow of communication. The significant difference between the explicit (segmented) recast and the implicit one was the former type's noticieability. The following is an example of the interaction between one of the students and the teacher:

$\mathrm{T}$ : when do you get promoted?
S: I think I will receive my promotion by next November.

T: ERM.... You will have received your promotion by next November.

As it is apparent in the example, there is no interruption or emphasis in the flow of communication. So, it is quite possible for the students to take the teacher's utterance as a confirmation of what they had said.

* No Recast Group (NRG). In this study, NRG considered to be the control group, the group in which errors were ignored by the teacher and none of the recast types was used. An example follows:

T: Have you watched TITANIC movie?

S: Yes. I watched it.

T: Oh, Really? How was it?

After the treatment sessions it was time for assessing the usefulness of instruction. Two important objectives, inspired by the research hypotheses, were of great interest: whether recast types had differential effects on the acquisition of simple perfect tenses (first hypothesis) and whether any outcome variable or any combination of them could separate explicit and implicit groups from each other (second research hypothesis). To this end, participants in all three groups were given posttests which were exactly the same as tests which had been given to them at the pretest stage. Of the 50 items in the posttest 24 directly addressed the three target structures, eight for each tense type. As practiced in the pretests, 60 minutes were given to the students get the tests completed. Having completed the tests, the answer sheets were collected and scored. The final step was to analyze the data statistically.

\section{Data Analysis}

The participants of this study were selected from among intermediate students of English language, as determined by the proficiency test referred to above. After student's assignment to different groups and administering pretests, the normality of scores, which is an important assumption of parametric tests, was checked by running 1-sample K-S tests and P-P plots. The following table and figure show the results of the tests and the associated P-P plots.

Table 1. Tests of Normality of Scores' Distributions at Pretest Stage.

\begin{tabular}{|c|c|c|c|c|}
\hline \multicolumn{5}{|c|}{ One-sample kolmogorov-smirnov test } \\
\hline & & $\begin{array}{l}\text { Pretest } \\
\text { implicit } \\
\text { group }\end{array}$ & $\begin{array}{l}\text { Pretest } \\
\text { explicit } \\
\text { group }\end{array}$ & $\begin{array}{l}\text { Pretest } \\
\text { control } \\
\text { group }\end{array}$ \\
\hline \multicolumn{2}{|l|}{$\mathrm{N}$} & 15 & 15 & 15 \\
\hline \multirow{2}{*}{$\begin{array}{l}\text { Normal } \\
\text { Parameters }\end{array}$} & Mean & 3.1333 & 4.4667 & 3.4 \\
\hline & $\begin{array}{l}\text { Std. } \\
\text { Deviation }\end{array}$ & 3.18179 & 3.13657 & 3.86929 \\
\hline \multicolumn{2}{|c|}{ Kolmogorov-Smirnov Z } & 1.092 & 0.855 & 1.072 \\
\hline \multicolumn{2}{|c|}{ Asymp. Sig. (2-tailed) } & 0.184 & 0.457 & 0.2 \\
\hline
\end{tabular}

a. Test distributions are normal. 
Normal P-P Plot of pretest explicit group

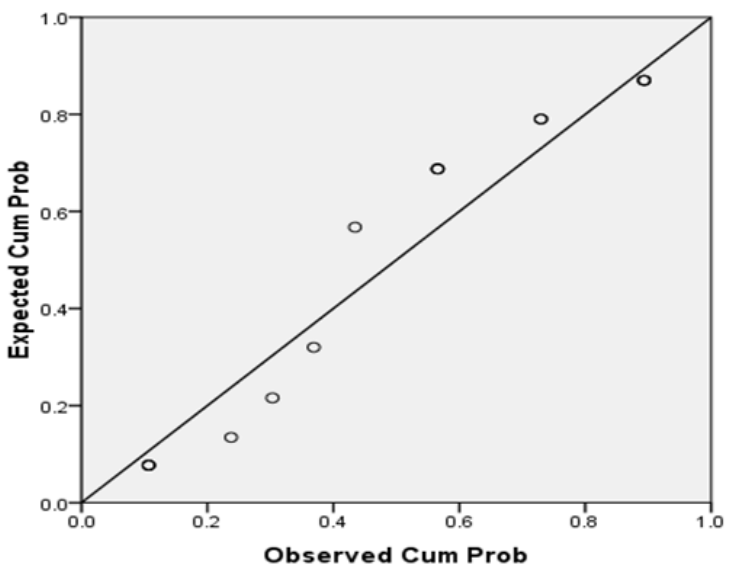

Normal P-P Plot of pretest implicit group[

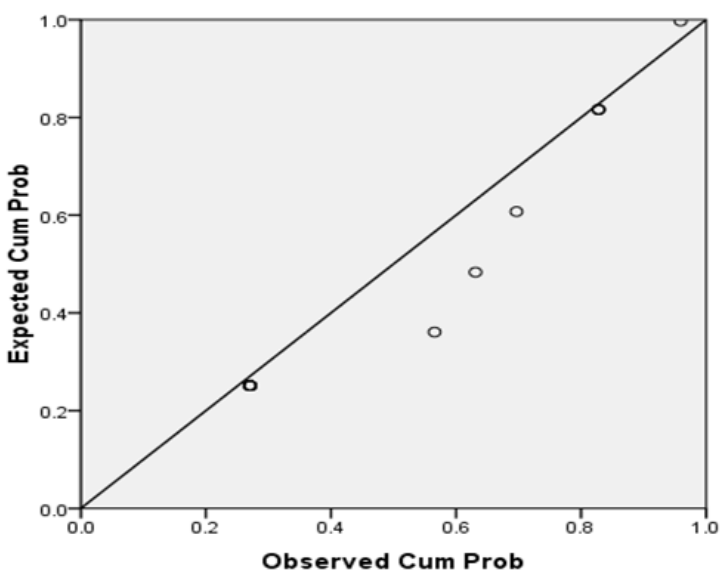

Normal P-P Plot of pretest control group

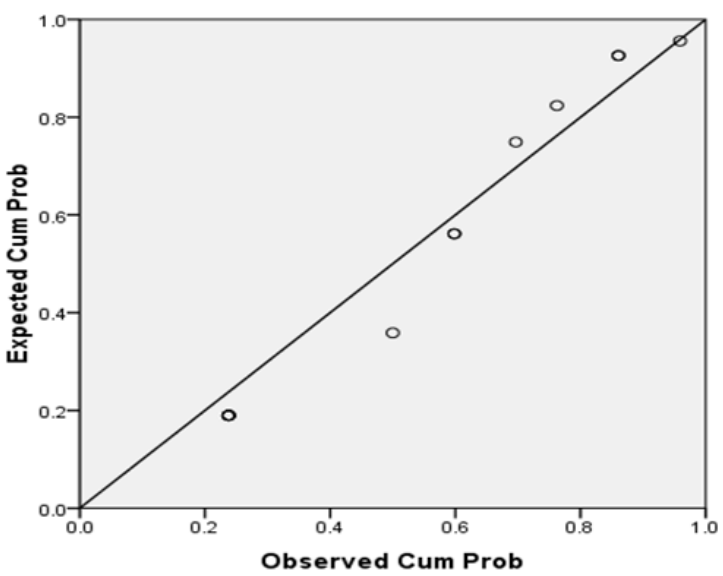

Figure 1. Probability-plots representing the normality of distributions.

The figure shows the normality of scores diagrammatically. It should be noted that in P-P plots the dots should not deviate from the model line. If the dots sag or rise above the line consistently, the distribution cannot be considered as normal.

After obtaining non-significant results in normality tests and checking the distributions visually, a One-way ANOVA test accompanied a by homogeneity test was run to see if the groups were homogeneous and the means of their scores were not substantially different from each other.

The lack of significant differences among means was also examined by a means plot. A close inspection of the values on means plot's $Y$ axis reveals that means are not dramatically different. The homogeneity table and the accompanying means plot are given below.

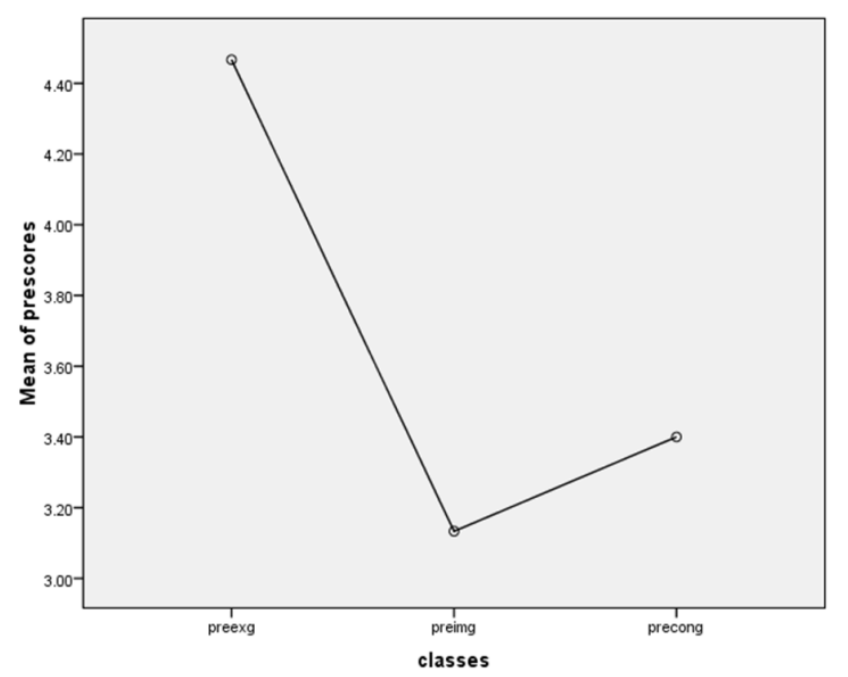

Figure 2. Means of pretest scores of IRG, ERG and NRG.

Running Multivariate Analysis of Variance (MANOVA) was the next step in our statistical analysis. Simple ANOVA is inadequate in circumstances in which we have several dependent variables. Unlike ANOVA that deals only with one dependent variable, MANOVA helps us to deal with more than one dependent variable at the same time and gather additional information about correlations that might exist between the dependent variables by including all of them in the same analysis. According to Field (2009, p. 586) "ANOVA can tell us only whether groups differ along a single dimension whereas MANOVA has the power to determine whether groups differ along a combination of dimensions." Applied to this study, ANOVA would tell us how scores on one of the dependent variables, say, simple present perfect, separates groups of participants. MANOVA, on the other hand, will incorporate information about all outcome measures (all three simple perfect tenses in this study) and will inform us whether groups of participants can be distinguished by a combination of scores. For example, it may not be possible to find out whether explicit feedback is better than implicit feedback just by looking at one of the tenses studied. The difference of these two types of teaching might be understood by a combination of students' scores on all three dependent variables.

Table 2. Test of Homogeneity of Variances.

\begin{tabular}{llll}
\hline Pretest Scores & & & \\
\hline Levene Statistic & df1 & df2 & Sig. \\
1.181 & 2 & 42 & 0.317 \\
\hline
\end{tabular}


Before running MANOVA, however, it was necessary to check for the remaining assumptions of this test. Our Leven's test in Table 2 above showed a non-significant result for homogeneity. This guarantees the reliability of univariate tests and also enables us to make a case for the robustness of the multivariate test statistics. Also, Since MANOVA is sensitive to outliers; we have to check if there are univariate and multivariate outliers. To this end, Mahal and Cook's distances should be calculated which tell us about the existence of such outliers and the normality of residuals' distributions. Table 3 shows the results of these tests generated using the regression menu in SPSS.

Table 3. Test of Checking Multivariate Normality.

\begin{tabular}{|c|c|c|c|c|c|}
\hline \multicolumn{6}{|c|}{ Residuals Statistics $^{\mathrm{a}}$} \\
\hline & Minimum & Maximum & Mean & $\begin{array}{l}\text { Std. } \\
\text { Deviation }\end{array}$ & $\mathbf{N}$ \\
\hline $\begin{array}{l}\text { Mahal. } \\
\text { Distance }\end{array}$ & 0.192 & 9.584 & 2.9 & 2.665 & 30 \\
\hline $\begin{array}{l}\text { Cook's } \\
\text { Distance } \\
\text { a. Depen }\end{array}$ & $\begin{array}{l}0 \\
\text { t Variable: }\end{array}$ & $\begin{array}{l}0.716 \\
\text { egories }\end{array}$ & 0.066 & 0.152 & 30 \\
\hline
\end{tabular}

Maximum Mahal distance, in this study, is 9.58 which does not exceed the critical value of 13.82 for twoindependent variables. Mahalanobis distances measure the distance of cases from a centroid calculated from the means of predictors or independent variables. The maximum Cook's distance, which is a measure of the overall influence of a case on the model, also is not bigger than one which points to the lack of outliers. The results of these two tests mean that univariate normality and multivariate normality were guaranteed. The Matrix of scatter plots has also been generated to check for the presence of a straight-line correlation between each pair of dependent variables. The graph below depicts the relative linearity of correlations.

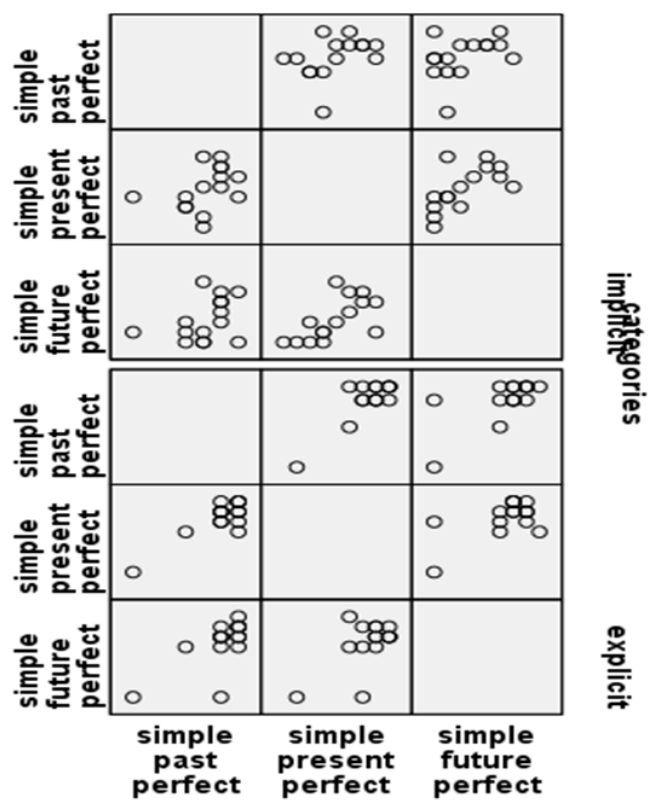

Figure 3. Linearity matrix scatter plots.
However, due to the small number of participants in the study, Figure 3 is not as revealing as it should be; therefore separate correlation tables were generated to affirm the linearity assumption. Tables4, 5, and 6 below show the results of these tests.

Table 4. Correlation between Simple Present Perfect and Simple Future Perfect.

\begin{tabular}{llll}
\hline Correlations & & Simple present \\
& & $\begin{array}{l}\text { Simple future } \\
\text { perfect }\end{array}$ \\
\hline & & Pearson & $.737^{* *}$ \\
simple present & $\begin{array}{l}\text { Correlation } \\
\text { perfect }\end{array}$ & 1 & 0 \\
& $\begin{array}{l}\text { Sig. (2-tailed) } \\
\text { N }\end{array}$ & 30 & 30 \\
$* *$ Correlation is significant at the 0.01 level (2-tailed). & \\
\hline
\end{tabular}

Table 5. Correlations between Simple Present Perfect and Simple Past Perfect.

\begin{tabular}{|c|c|c|c|}
\hline \multicolumn{4}{|l|}{ Correlations } \\
\hline & & $\begin{array}{l}\text { Simple present } \\
\text { perfect }\end{array}$ & $\begin{array}{l}\text { Simple past } \\
\text { perfect }\end{array}$ \\
\hline \multirow{3}{*}{$\begin{array}{l}\text { simple present } \\
\text { perfect }\end{array}$} & $\begin{array}{l}\text { Pearson } \\
\text { Correlation }\end{array}$ & 1 & \\
\hline & Sig. (2-tailed) & & 0 \\
\hline & $\mathrm{N}$ & 30 & 30 \\
\hline
\end{tabular}

Table 6. Correlation between Simple Past Perfect and Simple Future Perfect.

\begin{tabular}{|c|c|c|c|c|}
\hline \multicolumn{5}{|c|}{ Correlations } \\
\hline & & & $\begin{array}{l}\text { Simple past } \\
\text { perfect }\end{array}$ & $\begin{array}{l}\text { Simple future } \\
\text { perfect }\end{array}$ \\
\hline \multirow{3}{*}{$\begin{array}{l}\text { simple } \\
\text { perfect }\end{array}$} & & $\begin{array}{l}\text { Pearson } \\
\text { Correlation }\end{array}$ & 1 & $.584^{* *}$ \\
\hline & & Sig. (2-tailed) & & 0.001 \\
\hline & & $\mathrm{N}$ & 30 & 30 \\
\hline
\end{tabular}

Obtaining Box's Test was the next step to tell whether the data violated the assumption of homogeneity of variance covariance matrices. This statistic either accepts or rejects the null hypothesis of covariance matrices equality in all three groups. If the statistic is non-significant, it can be concluded that the matrices are the same. The table below reveals that the assumption of homogeneity is tenable.

Table 7. Box's Test of Equality of Covariance Matrices ${ }^{a}$.

\begin{tabular}{ll}
\hline Box's M & 8.803 \\
F & 1.295 \\
df1 & 6 \\
df2 & 5680.302 \\
Sig. & 0.255 \\
a. Design: Intercept + categories manova \\
\hline
\end{tabular}

The final stage was running MANOVA itself to detect the differences in the effects of explicit and implicit recasts on combined dependent variables, on the one hand, and to see if the dependent variables in isolation or together can differentiate between the groups depending on the nature of the tenses. Exploring these two situations could have made us capable of rejecting or accepting our hypotheses. 
According to Fidel (2009) Multivariate Tests' table is the main table of MANOVA. In this table statistics are quoted for the intercept of the model (which are not important for us) and for the group variable, in the case of our study explicit versus implicit situations. The group effects are important because they tell us whether or not our different methods of teaching had an effect. SPSS lists four multivariate test statistics. In the next column the $F$-ratios are given with degrees of freedom. The column we are interested in, however, is the one containing the significance values of $F$ ratios. If all of the four multivariate test statistics reach the criterion for significance, we can confidently reject the null hypothesis that there is no significant difference with respect to groups' effects. However, if we find mixed results, the best choice for accepting or rejecting the hypothesis is the robust test of Pilla's trace. From the results that we have obtained in our Multivariate Tests' table, therefore we can conclude that the type of teaching had an effect on students' simple perfect proficiency but first we do not know which group differed from which and second whether the effect of teaching type was on the simple past, present, or future perfect tense. To determine the nature of the effect we have to look at the univariate test results. Table 8 shows the results of multivariate tests, while Table 9 represents the univariate results.

Table 8. Results of Multivariate Tests.

\begin{tabular}{lllllll}
\hline Multivariate Tests $^{\mathbf{b}}$ & & & & & \\
\hline Effect & & Value & F & Hypothesis df & Error df & Sig. \\
\hline \multirow{4}{*}{ Intercept } & Pillai's Trace & 0.952 & $171.408^{\mathrm{a}}$ & 3 & 26 & 0 \\
& Wilks' Lambda & 0.048 & $171.408^{\mathrm{a}}$ & 3 & 26 & 0 \\
& Hotelling's Trace & 19.778 & $171.408^{\mathrm{a}}$ & 3 & 26 & 0 \\
& Roy's Largest Root & 19.778 & $171.408^{\mathrm{a}}$ & 3 & 26 & 0 \\
Categories & Pillai's Trace & 0.403 & $5.842^{\mathrm{a}}$ & 3 & 26 & 0.003 \\
& Wilks' Lambda & 0.597 & $5.842^{\mathrm{a}}$ & 3 & 26 & 0.003 \\
\multicolumn{1}{l}{ a. Exact statistic } & Hotelling's Trace & 0.674 & $5.842^{\mathrm{a}}$ & 3 & 26 & 0.003 \\
b. Design: Intercept & Roy's Largest Root & 0.674 & $5.842^{\mathrm{a}}$ & 3 & 26 & 0.003 \\
\hline
\end{tabular}

Table 9. MANOVA.

\begin{tabular}{|c|c|c|c|c|c|c|c|}
\hline \multicolumn{8}{|c|}{ Tests of Between-Subjects Effects } \\
\hline Source & Dependent Variable & Type III Sum of Squares & Df & Mean Square & $\mathbf{F}$ & Sig. & Partial Eta Squared \\
\hline \multirow{3}{*}{$\begin{array}{l}\text { Corrected } \\
\text { Model }\end{array}$} & simple past perfect & $5.633^{\mathrm{a}}$ & 1 & 5.633 & 2.329 & 0.138 & 0.077 \\
\hline & simple present perfect & $48.133^{\mathrm{b}}$ & 1 & 48.133 & 12.327 & 0.002 & 0.306 \\
\hline & simple future perfect & $73.633^{\mathrm{c}}$ & 1 & 73.633 & 14.883 & 0.001 & 0.347 \\
\hline \multirow{3}{*}{ Intercept } & simple past perfect & 1293.633 & 1 & 1293.633 & 534.77 & 0 & 0.95 \\
\hline & simple present perfect & 790.533 & 1 & 790.533 & 202.454 & 0 & 0.879 \\
\hline & simple future perfect & 440.833 & 1 & 440.833 & 89.1 & 0 & 0.761 \\
\hline \multirow{3}{*}{ Categories } & simple past perfect & 5.633 & 1 & 5.633 & 2.329 & 0.138 & 0.077 \\
\hline & simple present perfect & 48.133 & 1 & 48.133 & 12.327 & 0.002 & 0.306 \\
\hline & simple future perfect & 73.633 & 1 & 73.633 & 14.883 & 0.001 & 0.347 \\
\hline \multirow{3}{*}{ Error } & simple past perfect & 67.733 & 28 & 2.419 & & & \\
\hline & simple present perfect & 109.333 & 28 & 3.905 & & & \\
\hline & simple future perfect & 138.533 & 28 & 4.948 & & & \\
\hline \multirow{3}{*}{ Total } & simple past perfect & 1367 & 30 & & & & \\
\hline & simple present perfect & 948 & 30 & & & & \\
\hline & simple future perfect & 653 & 30 & & & & \\
\hline \multirow{3}{*}{$\begin{array}{l}\text { Corrected } \\
\text { Total }\end{array}$} & simple past perfect & 73.367 & 29 & & & & \\
\hline & simple present perfect & 157.467 & 29 & & & & \\
\hline & simple future perfect & 212.167 & 29 & & & & \\
\hline \multicolumn{8}{|c|}{ a. R Squared $=.077$ (Adjusted R Squared $=.044)$} \\
\hline \multicolumn{8}{|c|}{ b. R Squared $=.306($ Adjusted R Squared $=.281)$} \\
\hline
\end{tabular}

In fact, Table 9 is the ANOVA summary for the dependent variables. The row that we are interested in is labeled categories. This row contains an ANOVA summary table for each dependent variable and values are given for simple past, present, and future perfect tenses. The table also represents the $F$ and $S i g$ values for each dependent variable. The values in the categories row will be identical to those obtained if a One-way ANOVA was conducted on each dependent variable after applying the Benferroni adjustment. The non-significant result ( $p=.138$ ) for the simple past perfect should lead us to conclude that the type of teaching has had no significant effect on the acquisition of this tense. When the results for the dependent variables considered separately, significant results, however, can be seen for simple present perfect, $\mathrm{F}=$ $12.327, p=.002$, eta squared $=.306$, and simple future perfect, $\mathrm{F}=14.883, \mathrm{p}=.001$ and eta squared $=.347$.

These findings bring us to the point of concluding that explicit recasts differently affect the acquisition of simple present perfect and simple future perfect tenses if not the simple past perfect. This finding rejects our first null 
hypothesis that implicit and explicit recasts do not affect learners' acquisition of simple perfect tenses differently, because they do so at least with respect to two of these tenses.

Also knowing that the effect of implicit versus explicit is only related to the cumulated effect of the two tenses of simple present perfect and simple future perfect convinces us that the superiority of explicit teaching over implicit teaching is not the result of their differential effect on simple past tense. In other words our second hypothesis is accepted that explicit and implicit groups are not separated by a combination of scores on all dependent variables.

\section{Results and Discussion}

The findings of this study illustrated that explicit and implicit recasts both are effective in improving students' application of simple perfect tense application. However, in terms of usefulness, explicit recasts appeared to contribute more to the better and the most desirable performance of students than implicit recasts regarding the application of simple present perfect and simple future perfect tenses. It should be mentioned, however, that the findings of this study are only applicable to the grammatical points dealt with in this study. Whether, other tense forms will be affected by explicit and implicit recasts in the same way is a matter of more investigation.

Training all students to be fluent and accurate is an age-old desire. In order to materialize this wish, researchers have tried different ways. CFs are one of the most important ways by which teachers make their students understand about their linguistic problems. But there is a problem regarding the applicability of findings from studies related to CFs, especially recasts. Recasts which are claimed to account for 60 percent of all feedback moves in the classroom atmosphere have been largely recognized as an area of interest for most researches. Taking most of the pervious researches into consideration, one can conclude that there is still a need for exploring the connection between recasts and their effects on learning. This partial negligence was the impetus behind conducting this research.

Some research findings (Ammar et al., 2006; Mackey, 2000) have revealed that the noticeability of some implicit CFs such as recasts has got to do with learners' proficiency in the target language. There is a key question asking for the difference in effectiveness of various implicit and explicit forms of recasts. The findings of this and other related studies demonstrate that formal characteristics of recasts such as their explicitness or implicitness may truly influence their effectiveness.

This finding is in line with the findings of Loewen and Philip (2006) who examined the effects of different types of recasts on learners' performance. Explicit recasts that were stressed were significant predicators of accuracy of learners' posttest scores. The findings of this study, however, disagree with the findings of Jennifer Leeman (2003) whose findings confirmed the effectiveness of implicit recasts on students' performance in gender and number agreement. These findings suggest that the provision of implicit recasts which do not break down the flow of communication and are not stressed or partial can have beneficial outcomes. The findings of this research are also consistent with many pervious researches in recasts (e.g. Long et al., 1998, Mackey \& Philip, 1998).

\section{References}

[1] Ammar, A., \& Spada, N. (2006). One size fits all? Recasts, prompts, and L2 learning. Studies in Second Language Acquisition, 24, 543-544.

[2] Doughty, C., \& Williams, J. (1998). Pedagogical choices in focus on form. In C. Doughty \& J. Williams (Eds.), Focus on forming classroom second language (pp. 177-196). New York: Cambridge University Press.

[3] Field, A. (2009). Discovering statistics using SPSS: And sex and drugs and rock ' $n$ ' roll (3rded.). London: Sage Publications Ltd.

[4] Harley, B., \& Swain, M. (1984). The interlanguage of immersion students and its implication for second language teaching. In A. Davis, C. Criper, \&A.Howatt (Eds.), Interlanguage(pp. 291-311). Edinburgh: Edinburgh University Press.

[5] Ishida, M. (2004). Effects of recasts on the acquisition of the aspectual form of -Te (ru) by Learners of Japanese as a foreign language. Language Learning, 54,311-394.

[6] Leeman, J. (2003). Recasts and second language development: Beyond negative evidence.Studies in Second Language Acquisition, 25, 37-63.

[7] Lightbown, P. M., Halter, R. H., White, J. L., \& Horst, M. (2002). Comprehension-based learning: The limits of "do it yourself". Canadian Modern Language Review, 58, 427-464.

[8] Lightbown, P. M., \&Spada, N. (1990). Focus-on-form and corrective feedback in communicative language teaching: Effects on second language learning. Studies in Second Language Acquisition, 12, 429-448.

[9] Lightbown, P. M., \&Spada, N. (1994).An innovative for primary ESL in Quebec.TESOL Quarterly, 28,563-579.

[10] Loewen, S., \&Philp, J. (2006). Recast in The Adult English L2 Classroom: Characteristics,Explicitness, and effectiveness. The Modern Language Journal,90, 536-556.

[11] Long, M. H. (1991). Focus on form: A design feature in language teaching methodology. In K. D. Bot, C. Kramsch, \& R. Ginsberg (Eds.), Foreign language research in crosscultural perspective (pp. 39-52). Amsterdam: Benjamins.

[12] Long, M. (1996).The role of the linguistic environment in second language acquisition. In W.R., Ritchie and T.J., Bhatia (Eds.), Handbook of second language acquisition. 68413.Academic Press.

[13] Long, M. H., \& Robinson, P. (1998). Focus on form: Theory, research, and practice. In C. Doughty \& J. Williams (Eds.), Focus on forming classroom second language acquisition (pp. 21-26). Cambridge: Cambridge University Press. 
[14] Long, M., Inagaki, S., \& Ortega, L. (1998). The role of implicit negative feedback in SLA: Models and recasts in Japanese and Spanish. Modern Language Journal, 82, 357371.

[15] Lyster, R., \& Ranta, L. (1997). Corrective feedback and learner uptake. Studies in Second Language Acquisition, 19, $37-66$.

[16] Mackey, A. (2000). Interactional feedback on L2 morphosyntax: Learners' perceptions and developmental outcome. Paper presented at the annual meeting of AmericanAssociation for Applied Linguistic, Vancouver, B. C., Canada.

[17] Mackey, A., \& Philp, J. (1998). Conversational interaction and second language development. Recasts, responses, and red herrings? Modern Language Journal, 82,338-356.

[18] Moinzadeh, A., Rassaei, E., \& youhannaee, M. (2012). Recasts, modified output and L2 development: A case of Persian EFL. English Language and Literature Studies, 2, $100-111$.

[19] Pazoki, S., \& Seyed Rezaei, F. (2013). The role of recast on left hemisphere dominant vs. right hemisphere dominant Iranian EFL learners. Journal of Advances in English Language Teaching, 1, 47-58.
[20] Rutherford, W., \& Sharwood Smith, M. (1985). Consciousness-raising and universal grammar. Applied Linguistics, 6, 274-282.

[21] Schmit, R. (1983). Interaction, accumulation, and the acquisition communicative competence. In $\mathrm{n}$. Wolfson \& $\mathrm{E}$. Judd (Eds.), sociolinguistics and second language acquisition (pp. 85-103). Rowley, MA: Newbury House.

[22] Schmit, R.(1990). The role of consciousness in second language learning. Applied Linguistics, 13, 206-226.

[23] Schmit, R. (2001). Attention. In P. Robinson (Ed.), Cognitive and second language Instruction (pp. 1-32). Cambridge: Cambridge University Press.

[24] Spada, N. (1997). Formed-focused instruction and second language acquisition: A review of classroom and laboratory research. Language Teaching, 29, 1-15.

[25] White, L. (1987). Against comprehensible input: The input hypothesis and the development of L2 competence. Applied Linguistics, 8, 95-110. 